\title{
Optimization of High Pressure Coolant Assisted Turning of Inconel 718 using TOPSIS
}

\author{
S. Raykar ${ }^{1^{*}}$, U. Dabade ${ }^{2}$ \\ ${ }^{1}$ Research scholar, Walchand College of Engineering, Sangli, Maharashtra, India \\ ${ }^{2}$ Professor, Walchand College of Engineering, Sangli, Maharashtra, India \\ \{raykarsunil@gmail.com\}
}

\begin{abstract}
Optimization of process parameters for machining Heat Resistant Super Alloys (HRSA) is a very challenging task for researchers. Many techniques are being used to find out optimized process parameters for machining these alloys. This paper presents the use of Technique for Order Preference by Similarity to Ideal Solution (TOPSIS) to optimize process parameters for High-Pressure Coolant (HPC) assisted turning of Inconel 718.Inconel 718 is one of heat resistance superalloy from nickel-chromium group suitable for aerospace applications.TOPSIS is used for optimization of manufacturing processes which involves analysis of multiperformance characteristics. In the present analysis, high-pressure coolant is introduced into the cutting zone while machining Inconel 718.The performance of the machining is optimized for response variables namely cutting force, radial force, feed force and surface roughness. It is seen from the analysis that TOPSIS is a very striking approach for multiobjective optimization which can be effectively used for machining processes which always involves many process parameters. Optimized process parameters found during the investigation are 80 bar coolant pressure, $60 \mathrm{~m} / \mathrm{min}$ cutting speed, $0.1 \mathrm{~mm} / \mathrm{rev}$ feed and $0.5 \mathrm{~mm}$ of the depth of cut.
\end{abstract}

Keywords: TOPSIS, High Pressure Coolant, Surface Roughness, Cutting Forces, Inconel 718

\section{Introduction}

Inconel 718 is one of the Heat Resistant Super Alloy (HRSA) from Nickel-Chromium group suitable for aerospace applications. Apart from Nickel and Chromium it comprises of Iron, Niobium, Molybdenum, Aluminum and Titanium. It has outstanding physical properties like corrosion resistance, strength, weldability. Inconel 718 is commonly used in hot sections of gas turbines, rocket engines, spacecraft structural components, nuclear reactors, pumps, tooling, in the manufacture of components for aircraft turbine engines, cryogenic tankage and nuclear industries [1,2].

Inconel is considered as difficult to cut material because of poor thermal conductivity, high temperature strength, high shear strength and presence of abrasive carbide particles in the microstructure. During its machining the cutting tool often gets subjected to very high thermal and mechanical loads which cause rapid tool wear. Welding and sticking of worked material onto the cutting tool is a major problem during machining of Inconel 718 which causes rigorous notching and high cutting forces generates vibration while machining [35]. Because of above reasons lot of research is going on in the field of machining of Inconel 718 using different techniques like Cryogenic machining, Air jet assisted machining, Ultra High Speed Machining. Also researchers are investigating on use different tool materials and coatings which can minimize the tool wear. Apart from this it is extremely necessary to optimize the process parameters while machining Inconel 718 which can give improved performance of various responses during machining.

In High pressure coolant (HPC) assisted turning, coolant is supplied in machining zone at a very high pressure. When coolant is supplied at high pressure in cutting zone it can decrease cutting forces, increase life of cutting and provide superior machined surface. While machining of Inconel 718 with high-pressure coolant produces very small chips and offer extended tool life [6]. High pressure coolant can give enhanced machined surface with lower cutting forces because of better chip [7,8]. Chip segmentation is greatly influenced by coolant pressure used while machining Inconel 718. Well segmented C-shaped chips can be produced with high pressure coolant [9].

B. Iyer, S. Nalbalwar and R. Pawade (Eds.)

ICCASP/ICMMD-2016. Advances in Intelligent Systems Research.

Vol. 137, Pp. 113-120.

(C) 2017. The authors - Published by Atlantis Press

This is an open access article under the CC BY-NC license (http://creativecommons.org/licens)es/by-nc/4.0/).

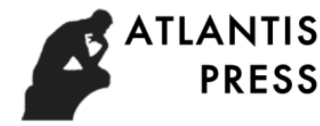


This paper presents use of Technique for Order Preference by Similarity to Ideal Solution (TOPSIS) to optimize the process parameters for high pressure assisted turning of Inconel 718.TOPSIS can be conveniently used for optimization of variety manufacturing processes which involves multi criteria decision making. Recently many researchers have used TOPSIS for multiobjective optimization of machining processes parameters.

Tripathy and Tripathy [10] implemented TOPSIS for multi-attribute optimization of Powder Mixed ElectroDischarge Machining (PMEDM). They found TOPSIS is appropriate to find out best possible solution for the set of input parameters which will give required performance characteristics. Singaravel and Selvaraj [11] determined optimum machining parameters in turning operation of EN25 steel with coated carbide tools using TOPSIS. In their investigation they used TOPSIS for finding out best set of machining parameters from available alternatives and Analytic Hierarchy Process (AHP) method was used to determine the weights of various attributes according to their objectives. According to Parida and Routara [12] TOPSIS approach can provide more reliable solutions as exact experimental values are used to represent the process. Also in TOPSIS simple statistical calculation are used to get the appreciable result.

\section{Details of Experiments}

\subsection{Experimental Procedure}

The experimental details are mentioned in Table 1

\section{Table 1 Experimental Details}

\begin{tabular}{|c|c|}
\hline $\begin{array}{l}\text { Workpiece Material and } \\
\text { Specifications }\end{array}$ & $\begin{array}{l}\text { Inconel } 718 \text { rods ( } 39 \text { HRc.) }(40 \mathrm{~mm} \\
\text { length and } 22 \mathrm{~mm} \text { diameter }) \text {, Cutting Length }=15 \mathrm{~mm} \text {. }\end{array}$ \\
\hline Machine & $\begin{array}{l}\text { CNC Turning Center (Experimental Set-up and Machined } \\
\text { components are shown in Fig. } 1 \text { and } 2 \text { respectively) }\end{array}$ \\
\hline Cutting Tool Insert & Sandvik make QM 1105, PVD coated CNMG 120408 \\
\hline High Pressure Coolant System & $\begin{array}{l}\text { A plunger type pump of maximum delivery pressure } 100 \text { bar is } \\
\text { used in the system. The maximum coolant flow rate of the pump } \\
\text { is } 7 \text { liters per minute (LPM).The nozzle is fixed to turret of } \\
\text { machine with a suitable fixture (Shown in Fig. 1).Coolant is } 5 \% \\
\text { oil water emulsion }\end{array}$ \\
\hline $\begin{array}{l}\text { Force Measurement (Cutting } \\
\text { force-Fx, Radial force-Fy and } \\
\text { Feed force-Fz) }\end{array}$ & Kistler 9257, three-component piezo-electric dynamometer \\
\hline $\begin{array}{l}\text { Surface Roughness } \\
\text { Measurement }\end{array}$ & $\begin{array}{l}\text { Mitutoyo SJ-210 with cut-off length of } 0.8 \mathrm{~mm} \text {. (With suitable } \\
\text { clamping arrangement shown in Fig. } 3 \text { ) }\end{array}$ \\
\hline
\end{tabular}

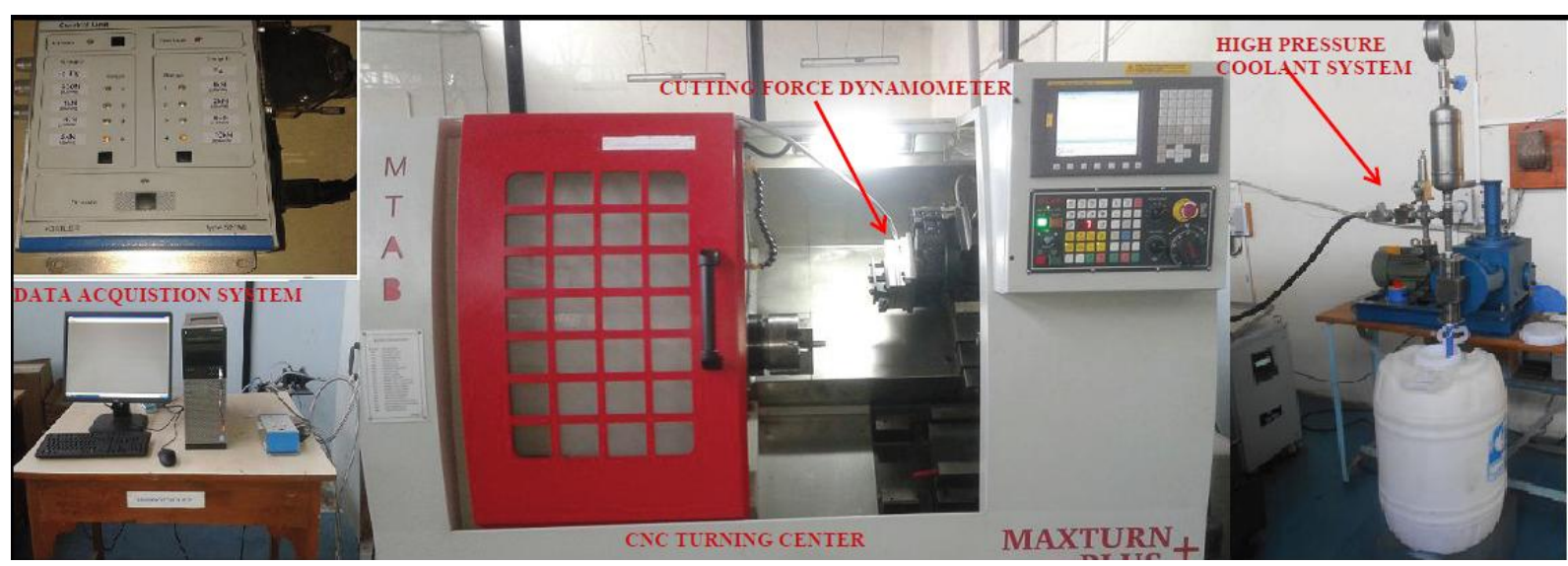


Fig. 1. Experimental Set-up with High Pressure Coolant System and Cutting Force Dynamometer

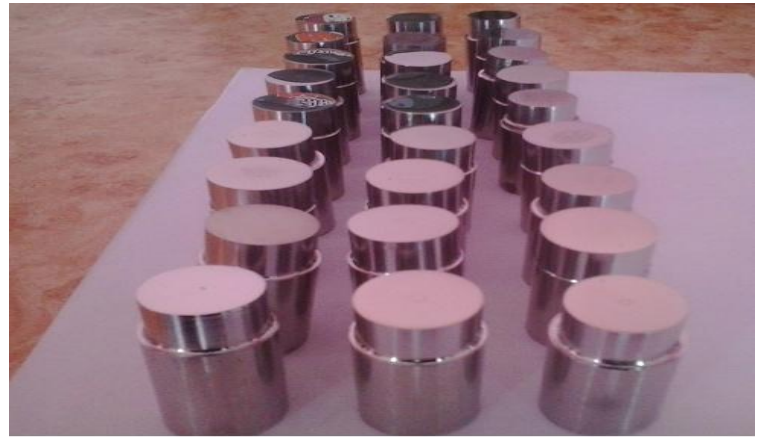

Fig. 2. Machined Components

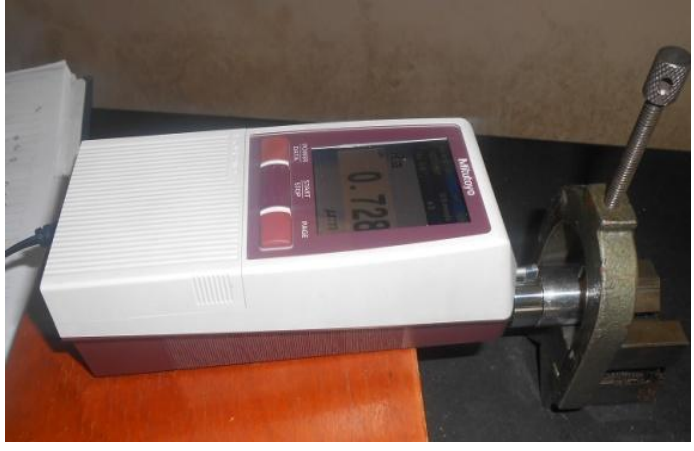

Fig. 3. Surface Roughness Measurement

\subsection{Experimental Design}

In this investigation Taguchi orthogonal array was used to design the experiment. The main focus of the investigation is on pressure of coolant, so apart from speed, feed, depth of cut, pressure of coolant is also taken as process parameter. Based on some trial experiment, available literature and from the insert manufacturer catalogue the levels of process parameters are selected. The parameters with their real values are shown in Table 2. The chosen array is $L_{27}$ with four factors at three levels each. The details of $L_{27}$ array is as shown in Table 3 .

Table 2 Levels of parameters with their real values

\begin{tabular}{|c|c|c|c|c|}
\hline Levels & $\begin{array}{c}\text { Pressure } \\
\text { (P) bar }\end{array}$ & $\begin{array}{c}\text { Speed (V) } \\
\mathbf{m} / \mathbf{m i n}\end{array}$ & $\begin{array}{c}\text { Feed (f) } \\
\mathbf{m m} / \mathbf{r e v}\end{array}$ & $\begin{array}{c}\text { Depth of Cut } \\
\text { (d) } \mathbf{~ m m ~}\end{array}$ \\
\hline 1 & 20 & 40 & 0.1 & 0.5 \\
\hline 2 & 50 & 60 & 0.15 & 1 \\
\hline 3 & 80 & 80 & 0.2 & 1.5 \\
\hline
\end{tabular}

Table 3 Taguchi $L_{27}$ array

\begin{tabular}{|c|c|c|c|c|c|c|c|c|}
\hline Exp. No & Pressure & Speed & Feed & DoC & Fx $(\mathbf{N})$ & $\mathbf{F y}(\mathbf{N})$ & $\mathbf{F z}(\mathbf{N})$ & $\mathbf{R a}(\boldsymbol{\mu m})$ \\
\hline 1 & 20 & 40 & 0.1 & 0.5 & 233.4 & 191.6 & 144.8 & 0.431 \\
\hline 2 & 20 & 40 & 0.1 & 1 & 413 & 225.9 & 288.1 & 0.588 \\
\hline 3 & 20 & 40 & 0.1 & 1.5 & 622 & 309.7 & 318.3 & 0.556 \\
\hline 4 & 20 & 60 & 0.15 & 0.5 & 280.7 & 207.1 & 144.8 & 0.837 \\
\hline 5 & 20 & 60 & 0.15 & 1 & 534.1 & 271.3 & 309.5 & 1.087 \\
\hline 6 & 20 & 60 & 0.15 & 1.5 & 789.7 & 310.5 & 477.3 & 0.997 \\
\hline 7 & 20 & 80 & 0.2 & 0.5 & 361 & 246.7 & 155.1 & 1.398 \\
\hline 8 & 20 & 80 & 0.2 & 1 & 617.1 & 293 & 322.2 & 1.695 \\
\hline 9 & 20 & 80 & 0.2 & 1.5 & 968.6 & 326.3 & 539.1 & 1.46 \\
\hline 10 & 50 & 40 & 0.15 & 0.5 & 291.2 & 228.9 & 150.2 & 0.935 \\
\hline 11 & 50 & 40 & 0.15 & 1 & 548.8 & 272.7 & 319 & 1.082 \\
\hline 12 & 50 & 40 & 0.15 & 1.5 & 784.3 & 282.4 & 479.7 & 0.997 \\
\hline 13 & 50 & 60 & 0.2 & 0.5 & 363.9 & 247.4 & 162.2 & 1.03 \\
\hline 14 & 50 & 60 & 0.2 & 1 & 638.7 & 281.1 & 314.6 & 1.2 \\
\hline 15 & 50 & 60 & 0.2 & 1.5 & 905.7 & 323 & 527.4 & 1.588 \\
\hline
\end{tabular}




\begin{tabular}{|c|c|c|c|c|c|c|c|c|}
\hline 16 & 50 & 80 & 0.1 & 0.5 & 199.8 & 173.1 & 117.1 & 0.461 \\
\hline 17 & 50 & 80 & 0.1 & 1 & 409.4 & 224.9 & 294.4 & 0.983 \\
\hline 18 & 50 & 80 & 0.1 & 1.5 & 580.5 & 241.4 & 415.5 & 0.839 \\
\hline 19 & 80 & 40 & 0.2 & 0.5 & 337.5 & 213.2 & 226.1 & 1.159 \\
\hline 20 & 80 & 40 & 0.2 & 1 & 619.9 & 243.8 & 256.1 & 1.301 \\
\hline 21 & 80 & 40 & 0.2 & 1.5 & 836 & 320.5 & 440.6 & 1.259 \\
\hline 22 & 80 & 60 & 0.1 & 0.5 & 164.3 & 159 & 93.32 & 0.4 \\
\hline 23 & 80 & 60 & 0.1 & 1 & 326 & 233.1 & 145.5 & 0.449 \\
\hline 24 & 80 & 60 & 0.1 & 1.5 & 479.9 & 229.3 & 343.9 & 0.571 \\
\hline 25 & 80 & 80 & 0.15 & 0.5 & 255.7 & 198.6 & 126.5 & 0.723 \\
\hline 26 & 80 & 80 & 0.15 & 1 & 515.8 & 272.4 & 309.4 & 0.929 \\
\hline 27 & 80 & 80 & 0.15 & 1.5 & 752.7 & 279.9 & 458.3 & 1.039 \\
\hline
\end{tabular}

\section{Methodology of Optimization using TOPSIS [10-13]}

Step 1 Formulation of Decision Matrix: A decision matrix is formed from the given set of attributes. Here each row indicates an alternative and each column indicates an attribute. Therefore, an element $\mathrm{h}_{\mathrm{ij}}$ of the decision table provide real values the value of the $\mathrm{j}^{\text {th }}$ attribute in for the $\mathrm{i}^{\text {th }}$ alternative.

The decision matrix $\mathrm{D}_{\mathrm{m}}$ can be given as

$$
\mathrm{D}_{\mathrm{m}}=\left[\begin{array}{cccccc}
\mathrm{h}_{11} & \mathrm{~h}_{12} & \mathrm{~h}_{13} & . . & . . & \mathrm{h}_{1 \mathrm{n}} \\
\mathrm{h}_{21} & \mathrm{~h}_{22} & \mathrm{~h}_{23} & . . & . . & \mathrm{h}_{2 \mathrm{n}} \\
\mathrm{h}_{31} & \mathrm{~h}_{32} & \mathrm{~h}_{33} & . . & . . & \mathrm{h}_{3 n} \\
: & : & : & . . & . . & : \\
: & : & : & . . & . . & : \\
\mathrm{h}_{\mathrm{m} 1} & \mathrm{~h}_{\mathrm{m} 2} & \mathrm{~h}_{\mathrm{m} 3} & . . & . . & \mathrm{h}_{\mathrm{mn}}
\end{array}\right]
$$

Step 2 Normalization of Decision Matrix: After formation of decision matrix all the elements are normalized by using equation and a normalized decision matrix $\mathrm{r}_{\mathrm{ij}}$ is obtained

$$
\mathrm{r}_{\mathrm{ij}}=\frac{\mathrm{h}_{\mathrm{ij}}}{\sqrt{\sum_{\mathrm{i}=1}^{\mathrm{m}} \mathrm{h}_{\mathrm{ij}}{ }^{2}}}
$$

Step 3 Weight for each response is calculated: Depending on the relative importance of each response, weight can be assigned to each attribute.A set of weights to all attributes is decided such that summation all weights must be one.

Step 4 Formation of Weighted Normalized matrix: A Weighted Normalized matrix is the formed by multiplying each column of normalized matrix $r_{i j}$ with the corresponding weights. A weighted Normalized matrix is given as

$$
\mathrm{V}=\mathrm{w}_{\mathrm{j}} \mathrm{r}_{\mathrm{ij}}(2)
$$




$$
\sum_{j=1}^{n} w_{j}=1
$$

Step 5 Determination of Positive and Negative Ideal Solutions: A positive ideal solution is given as

$$
\begin{aligned}
& \mathrm{V}^{+}=\left\{\left(\sum_{\mathrm{i}}^{\mathrm{max}} \mathrm{v}_{\mathrm{ij}} \mid \mathrm{j} \in \mathrm{J}\right),\left(\sum_{\mathrm{i} \mid}^{\mathrm{min}} \mathrm{j} \in \mathrm{J} \mid \mathrm{i}=1,2, \ldots . . \mathrm{m}\right)\right\} \\
& =\left\{\mathrm{v}_{1}{ }^{+}, \mathrm{v}_{2}{ }^{+}, \mathrm{v}_{3}{ }^{+} \ldots \ldots \ldots \ldots \ldots \ldots \ldots \ldots \ldots, \mathrm{v}_{\mathrm{n}}{ }^{+}\right\}
\end{aligned}
$$

$\mathrm{V}^{+}$indicates the best value of the attribute among the values of all attribute for different alternatives under investigation.

A negative ideal solution is given as

$$
\begin{aligned}
\mathrm{V}^{-} & =\left\{\left(\sum_{\mathrm{i}}^{\mathrm{min}} \mathrm{v}_{\mathrm{ij}} \mid \mathrm{j} \in \mathrm{J}\right),\left(\sum_{\mathrm{i} \mid}^{\mathrm{max}} \mathrm{j} \in \mathrm{J} \mid \mathrm{i}=1,2, \ldots . \mathrm{m}\right)\right\} \\
& =\left\{\mathrm{v}_{1}^{-}, \mathrm{v}_{2}^{-}, \mathrm{v}_{3}^{-} \ldots \ldots \ldots \ldots \ldots \ldots \ldots \ldots \ldots, \mathrm{v}_{\mathrm{n}}{ }^{-}\right\}
\end{aligned}
$$

V'Indicates the worst value of the attribute among the values of all attribute for different alternatives under

\begin{tabular}{|c|c|c|c|c|}
\hline $\begin{array}{c}\text { Exp. } \\
\text { No } \\
\end{array}$ & $\mathrm{S}_{\mathrm{i}}^{+}$ & $\mathrm{S}_{\mathrm{i}}^{-}$ & $\mathbf{P}_{\mathbf{i}}$ & Rank \\
\hline 1 & 0.0116 & 0.1080 & 0.9031 & 3 \\
\hline 2 & 0.0393 & 0.0823 & 0.6765 & 9 \\
\hline 3 & 0.0596 & 0.0699 & 0.5398 & 15 \\
\hline 4 & 0.0256 & 0.0955 & 0.7889 & 6 \\
\hline 5 & 0.0595 & 0.0592 & 0.4988 & 16 \\
\hline 6 & 0.0884 & 0.0377 & 0.2992 & 24 \\
\hline 7 & 0.0531 & 0.0803 & 0.6021 & 12 \\
\hline 8 & 0.0837 & 0.0446 & 0.3479 & 21 \\
\hline 9 & 0.1128 & 0.0115 & 0.0926 & 26 \\
\hline 10 & 0.0314 & 0.0917 & 0.7451 & 7 \\
\hline 11 & 0.0609 & 0.0577 & 0.4862 & 17 \\
\hline 12 & 0.0868 & 0.0386 & 0.3076 & 23 \\
\hline 13 & 0.0392 & 0.0842 & 0.6822 & 8 \\
\hline 14 & 0.0685 & 0.0505 & 0.4245 & 20 \\
\hline 15 & 0.1112 & 0.0076 & 0.0643 & 27 \\
\hline 16 & 0.0060 & 0.1121 & 0.9490 & 2 \\
\hline 17 & 0.0474 & 0.0717 & 0.6019 & 13 \\
\hline 18 & 0.0654 & 0.0577 & 0.4687 & 19 \\
\hline 19 & 0.0445 & 0.0789 & 0.6395 & 10 \\
\hline 20 & 0.0645 & 0.0573 & 0.4701 & 18 \\
\hline 21 & 0.0927 & 0.0280 & 0.2317 & 25 \\
\hline 22 & 0.0003 & 0.1181 & 0.9974 & 1 \\
\hline 23 & 0.0213 & 0.1014 & 0.8264 & 5 \\
\hline 24 & 0.0489 & 0.0758 & 0.6080 & 11 \\
\hline 25 & 0.0191 & 0.1012 & 0.8412 & 4 \\
\hline
\end{tabular}
investigation

Table 4 Decision Matrix and Corresponding Separation Measure from Positive and Negative ideal solution with Relative Closeness Coefficient

\begin{tabular}{|cccc}
\multicolumn{5}{c}{ Decision Matrix } \\
\hline 233.4 & 191.6 & 144.8 & 0.431 \\
413 & 225.9 & 288.1 & 0.588 \\
622 & 309.7 & 318.3 & 0.556 \\
280.7 & 207.1 & 144.8 & 0.837 \\
534.1 & 271.3 & 309.5 & 1.087 \\
789.7 & 310.5 & 477.3 & 0.997 \\
361 & 246.7 & 155.1 & 1.398 \\
617.1 & 293 & 322.2 & 1.695 \\
968.6 & 326.3 & 539.1 & 1.46 \\
291.2 & 228.9 & 150.2 & 0.935 \\
548.8 & 272.7 & 319 & 1.082 \\
784.3 & 282.4 & 479.7 & 0.997 \\
363.9 & 247.4 & 162.2 & 1.03 \\
638.7 & 281.1 & 314.6 & 1.2 \\
905.7 & 323 & 527.4 & 1.588 \\
199.8 & 173.1 & 117.1 & 0.461 \\
409.4 & 224.9 & 294.4 & 0.983 \\
580.5 & 241.4 & 415.5 & 0.839 \\
337.5 & 213.2 & 226.1 & 1.159 \\
619.9 & 243.8 & 256.1 & 1.301 \\
836 & 320.5 & 440.6 & 1.259 \\
164.3 & 159 & 93.32 & 0.4 \\
326 & 233.1 & 145.5 & 0.449 \\
479.9 & 229.3 & 343.9 & 0.571 \\
255.7 & 198.6 & 126.5 & 0.723 \\
515.8 & 272.4 & 309.4 & 0.929 \\
752.7 & 279.9 & 458.3 & 1.039
\end{tabular} \mid




\begin{tabular}{|l|l|l|l|l|}
\hline 26 & 0.0550 & 0.0641 & 0.5380 & 14 \\
\hline 27 & 0.0835 & 0.0391 & 0.3187 & 22 \\
\hline
\end{tabular}

Step 6: Calculation of separation measure from positive and negative ideal solution: - Separation Measure from Positive and Negative ideal is given by

$$
\mathrm{S}_{\mathrm{i}}^{+}=\sqrt{\sum_{\mathrm{j}=1}^{\mathrm{n}}\left(\mathrm{v}_{\mathrm{ij}}-\mathrm{v}_{\mathrm{j}}^{+}\right) 2} \quad, \mathrm{i}=1,2,3, \ldots \ldots \mathrm{m}
$$

$$
\mathrm{S}_{\mathrm{i}}{ }^{-}=\sqrt{\sum_{\mathrm{j}=1}^{\mathrm{n}}\left(\mathrm{v}_{\mathrm{ij}}-\mathrm{v}_{\mathrm{j}}{ }^{-}\right) 2} \quad, \mathrm{i}=1,2,3, \ldots \ldots \mathrm{m}
$$

Step 7: Calculation of Relative Closeness Coefficient of each alternative:-The relative closeness coefficient of each alternative is given by

$$
\mathrm{P}_{\mathrm{i}}=\frac{\mathrm{S}_{\mathrm{i}}^{-}}{\mathrm{S}_{\mathrm{i}}^{+}+\mathrm{S}_{\mathrm{i}}^{-}}
$$

\section{Results and Discussion}

The measured values of cutting force, radial force, feed force, surface roughness and tool wear (flank wear) are as shown in Table 3. For optimization of these multiple characteristics TOPSIS analysis is done on the experimental data. A decision matrix is formulated for all responses which is shown in Table 4. After formation of decision matrix it is normalized by using equation 1 . Weight for each response is assigned arbitrarily, since in this investigation four responses are there for every response a weight of 0.25 is assigned. After this, weighted normalized matrix is the formed by using equation 2 . It is formed by multiplying each column of normalized matrixwith the corresponding weights. Positive and Negative Ideal Solutions are determined by equations 3 and 4 respectively. Separation measures are derived from positive and negative ideal solution using equations 5 and 6.Finally Relative Closeness Coefficient of all alternative are determined with equation 7. After calculations of relative closeness coefficients analysis is done to find out optimum process parameters and their significance on relative closeness coefficients. For this purpose Response table, ANOVA and AOM plot for relative closeness coefficient is used. Fig. 4 indicates AOM plot for relative closeness coefficient, Table 5 and 6 shows response table and ANOVA for relative closeness coefficient respectively.

The main focus of this analysis is pressure of coolant, from analysis of data it is found that with increase in pressure of coolant, magnitude of cutting force components decreases with significant decrease in surface roughness. At high pressure chips found are more curled and spring type also high pressure of coolant is able to break the chips into small pieces and keeps them away from cutting zone which also decreases the length of contact with the tool which lowers the friction. This reduction in friction causes the cutting force to decrease. It is observed that a favourable decrease in cutting force ranging from 50 to $150 \mathrm{~N}$ can be achieved by increasing the coolant pressure upto 80 bar. Similarly radial force and feed force may decrease up to $80 \mathrm{~N}$ and $60 \mathrm{~N}$ respectively with increase in coolant pressure.

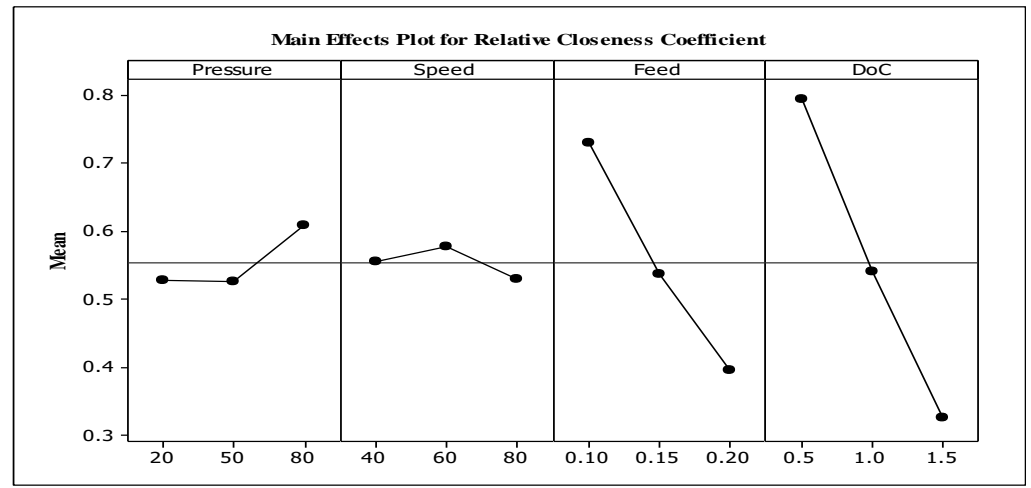


Fig. 4. AOM plot for Relative Closeness Coefficient

From response table 5 ANOVA and AOM plots it can be clearly seen that depth of cut has highest influence on all response variables. It is followed by feed, pressure of coolant and speed. From ANOVA it is clear that all depth of cut, feed and pressure of coolant are found to be significant at $95 \%$ confidence level for relative closeness coefficient. From response table of relative closeness coefficient it is clear that the optimal factor setting is $\mathrm{P}_{3} \mathrm{~V}_{2} \mathrm{f}_{1} \mathrm{~d}_{1}$, i.e. coolant pressure at level 3 (80 bar) cutting speed at level $2(60 \mathrm{~m} / \mathrm{min})$, feed rate at level $1(0.1 \mathrm{~mm} / \mathrm{rev})$, depth of cut at level $1(0.5 \mathrm{~mm})$. The sequence of significance for all parameters is shown in Table 5. At this optimized cutting parameters Cutting force is $164.3 \mathrm{~N}$, Radial Force is $159 \mathrm{~N}$, Feed Force is 93.32 $\mathrm{N}$ and Surface roughness is $0.4 \mu \mathrm{m}$.

Table 5 Response Table for Relative Closeness Coefficient

\begin{tabular}{|c|c|c|c|c|c|c|}
\hline Sr No & Factors & Level 1 & Level 2 & Level 3 & Max-Min & Rank \\
\hline 1 & Pressure & 0.5277 & 0.5255 & 0.6079 & 0.0824 & 3 \\
\hline 2 & Speed & 0.5555 & 0.5766 & 0.5289 & 0.0477 & 4 \\
\hline 3 & Feed & 0.7301 & 0.5360 & 0.3950 & 0.3351 & 2 \\
\hline 4 & DoC & 0.7943 & 0.5411 & 0.3256 & 0.4687 & 1 \\
\hline
\end{tabular}

Table 6 ANOVA for Relative Closeness Coefficient

\begin{tabular}{|l|l|l|l|l|l|l|}
\hline Source & DF & Seq SS & Adj SS & Adj MS & F & P \\
\hline Pressure & 2 & 0.0397 & 0.0397 & 0.0198 & 9.31 & $\mathbf{0 . 0 0 2}$ \\
\hline Speed & 2 & 0.0103 & 0.0103 & 0.0052 & 2.42 & $\mathbf{0 . 1 1 8}$ \\
\hline Feed & 2 & 0.5096 & 0.5096 & 0.2548 & 119.54 & $\mathbf{0 . 0 0 0}$ \\
\hline Depth of cut & 2 & 0.9905 & 0.9905 & 0.4953 & 232.37 & $\mathbf{0 . 0 0 0}$ \\
\hline Error & 18 & 0.0384 & 0.0384 & 0.0021 & & \\
\hline Total & 26 & 1.58839 & & & \\
\hline R-Sq-Sq(adj) $=\mathbf{9 6 . 5 1 \%}$ \\
\hline
\end{tabular}

\section{Conclusions}

Optimization of Turning of Inconel 718 with high pressure coolant is presented in this paper. Technique for Order Preference by Similarity to Ideal Solution (TOPSIS) is used for optimization purpose. Cutting force, Radial force, Feed force and Surface roughness are the responses for which cutting parameters with coolant pressure has been optimized. For the parameters under investigation depth of cut, feed and coolant pressure shows significant effect on multiple responses. Depth of cut is found to have most significant effect on the response variables. Depth of cut is followed by feed, pressure of coolant. However speed does not show significant effect on responses. From the analysis it is clear that coolant pressure is a very important consideration during machining of Inconel 718. The optimized parameters obtained from TOPSIS are 80 bar coolant pressure, $60 \mathrm{~m} / \mathrm{min}$ speed, $0.1 \mathrm{~mm} / \mathrm{rev}$ feed and $0.5 \mathrm{~mm}$ depth of cut.

\section{References}

[1]. Z.Y.Wang, K.P.Rajurkar, J. Fan, S.Lei, Y.C.Shin, G.Petrescu, "Hybrid machining of Inconel 718”,International Journal of Machine Tools \& Manufacture, 43(2003) 1391-1396.

[2]. C. Leone, D. D’Addona, R. Teti, “Tool wear modelling through regression analysis and intelligent methods

for nickel base alloy machining", CIRP Journal of Manufacturing Science and Technology 4 (2011) 327-331. 
[3]. A. Devillez, G. Le Coz, S. Dominiak, D. Dudzinski, "Cutting forces and wear in dry machining of Inconel 718 with coated carbide tools”, Wear 262 (2007) 931-942.

[4]. D. Dudzinski, A. Devillez, A. Moufki, D. Larrouquere, V. Zerrouki, J. Vigneau, “A review of developments towards dry and high speed machining of Inconel 718 alloy”, International Journal of Machine Tools \& Manufacture , 44 (2004) 439-456.

[5]. A. Sharman, R.C. Dewes, D.K. Aspinwall, "Tool life when high speed ball nose end milling Inconel”, Journals of Material Processing Technology,118 (2001) 29-35.

[6]. Z. Vagnorius, K. Sorby, "Effect of high-pressure cooling on life of SiSION tools in machining of Inconel 718”, Int J Adv Manuf Technol,54 (2011) 83-92.

[7]. O. Çolak, "Investigation on Machining Performance of Inconel 718 under High Pressure Cooling Conditions", Strojniski vestnik - Journal of Mechanical Engineering ,58(2012)11, 683-690.

[8]. C. Courbon, D.Kramar, P.Krajnik, F.Pusavec, J.Rech and J.Kopac, "Investigation of machining performance in high-pressure jet assisted turning of Inconel 718: An experimental study”, International Journal of Machine Tools \& Manufacture, 49 (2009) 1114-1125.

[9]. E.O. Ezugwu, J. Bonney, "Effect of high-pressure coolant supply when machining nickel-base, Inconel 718, alloy with coated carbide tools”, Journal of Materials Processing Technology ,153154 (2004) 1045-1050.

[10]. B. Singaravel, T. Selvaraj, "Optimization of machining parameters in turning operation using combined TOPSIS and AHP method", Tehnički vjesnik 22, 6(2015), 1475-1480, DOI: $10.17559 / \mathrm{TV}-20140530140610$.

[11]. S. Tripathy , D.K. Tripathy ,"Multi-attribute optimization of machining process parameters in powder mixe electro-discharge machining using TOPSIS and grey relational analysis", Engineering Science and Technology, an International Journal, 19 (2016) 62-70.

[12]. A. K. Parida and B. C. Routara, "Multiresponse Optimization of Process Parameters in Turning of GFRP Using TOPSIS Method", Hindawi Publishing Corporation International Scholarly Research Notices ,Volume 2014, http://dx.doi.org/10.1155/2014/905828.

[13]. R. Venkata Rao, Decision Making in the Manufacturing Environment Using Graph Theory and Fuzzy Multiple Attribute Decision Making Methods, Volume 2, Springer Series in Advanced Manufacturing Springer-Verlag London, 2013,pp10-13. 